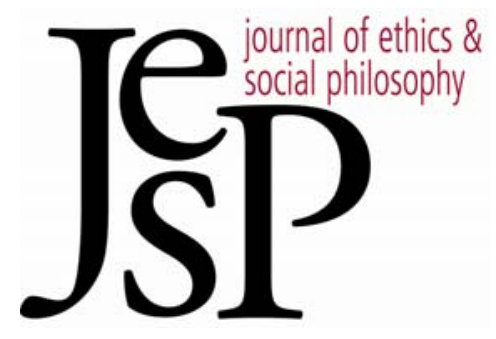

\title{
Moral PrinCiples ARE Not Moral LaWS
}

\author{
BY LUKE ROBINSON
}

Journal of Ethics \& Social PhILOSOPhy

Vol. 2, No. 3| NOVEMBER 2008 URL: WWW.JESP.ORG COPYRIGHT (C) LUKE ROBINSON 2008 


\section{Moral Principles Are Not Moral Laws} Luke Robinson*

\section{Introduction} - by which I mean generalizations or some special class thereof, such as explanatory or counterfactual-supporting generalizations. ${ }^{1}$ In this paper, I argue that this law conception of moral principles is mistaken: moral principles like promises ought to be kept and killing is wrong are not generalizations; nor are they what true generalizations describe, regularities; nor are they any special class of generalizations or regularities. In a slogan, moral principles are not moral laws.

After laying out the main argument of the paper, which is a burdenshifting argument against the law conception as such, I consider whether particular versions of that conception - particular conceptions of moral principles as moral laws - could answer it in ways that vindicate the law conception. I argue that none of the following could do so: a best-systems theory of moral principles based on the Mill-Ramsey-Lewis, or best-systems, theory of the so-called laws of nature; Sean McKeever and Michael Ridge's theory of moral principles as "action-guiding standards" (2006); Pekka Väyrynen's theory of moral principles as "hedged" generalizations (2006; 2008; 2009); and Mark Lance and Margaret Little's "pragmatist" theory of moral principles as "defeasible" generalizations (2008; 2007; 2006a; 2006b). I also argue that it is unlikely that the law conception could be vindicated, at least so long as the premises of the main argument are accepted. Finally, I conclude with some brief remarks about what moral principles might be if they are not moral laws: rules, relations between universals, or dispositions (powers, capacities, etc.). ${ }^{2}$

Before I proceed, two points of clarification are in order. First, in arguing that moral principles are not moral laws, I am not arguing that there are

\footnotetext{
* I would like to thank Eric Barnes, Steve Sverdlik, and Pekka Väyrynen for helpful comments on earlier drafts of this paper.

1 See, e.g., Crisp 2000, 34-5; Hooker 2000; Jackson, Pettit, and Smith 2000, 81-4; Lance and Little 2008; 2007; McKeever and Ridge 2006, 6, 7-8, 22-4; McNaughton and Rawling 2000, 269-75; Shafer-Landau 2003, 112, 248, 268-9 \& n. 2; 1997, 584-5; Väyrynen 2009, sec. 4; 2006, 716-7, 726-7. See also Brink 1994b, 215-20, 245; Pietroski 1993, 492, 499-500, 5145.

2 Here and elsewhere I use the term "disposition" as a generic term for dispositional properties: powers, capacities, tendencies, liabilities, etc. Some use "power" instead (e.g., Molnar 2003, 57).
} 
no moral laws. I do think there are moral laws as defined above, although I also think that most, if not all, of them hold true only ceteris paribus.

Second, I use the term "law" as a term of art (see above), which is in keeping with how it is generally used in the literature on the so-called laws of nature. In that literature, what is usually meant by a "law" is either a "lawlike" generalization or (less often) a "nomic" regularity described by such a generalization. The term is occasionally used in other ways - e.g., to refer to whatever serves as the truthmaker for "lawlike" generalizations, or to whatever grounds "nomic" regularities. For instance, when David Armstrong (1983) says that the laws of nature are neither generalizations nor regularities, but rather relations between universals, he is using "law" to mean something other than "lawlike" generalization or "nomic" regularity. But I follow the more common usage, in which Armstrong's (metaphysical) view of laws can be put this way: the laws of nature qua "lawlike" generalizations hold true in virtue of relations between universals (see, e.g., Ellis 2001, 215-6). Hence, one who conceived of moral principles as relations between universals would not hold a law conception of moral principles as defined above, nor would someone who conceived of such principles as rules (e.g., divine commands, precepts of reason, or social rules) or as dispositions (see section 7 below).

\section{Moral Principles Are Not Moral Laws}

As a preliminary matter, I grant that even if moral principles are not laws, they at least entail, give rise to, or otherwise guarantee laws, although these may hold true only ceteris paribus - or "for the most part" (Aristotle 1999, 1094b14-27). For instance, I grant that the moral principle

(POK) promises ought to be kept

at least guarantees that promises ought to be kept, ceteris paribus, and that the moral principle

(KW) killing is wrong

at least guarantees that killings (of persons) are wrong, ceteris paribus. Moreover, I grant that this is true whether moral principles such as POK and KW are best understood as true propositions, or as the truthmakers thereof, or as regularities, or as the grounds thereof. (There is, of course, the question of how we should understand such ceteris paribus clauses, but that need not detain us here.3)

Now to the argument. Moral principles do at least three things that mere regularities cannot do and, hence, that generalizations describing mere regularities cannot do, either. One thing that moral principles do is explain the

3 I address this question in Robinson MS. 
phenomena "falling within their scope," which scope at least includes the instances of the laws they guarantee. More specifically, moral principles explain why these phenomena obtain or occur. ${ }^{5}$ Take POK, for instance. One phenomenon it would explain is my obligation to remain faithful to my wife, as that is something I promised to do. Why am I obligated to remain faithful to my wife? Because promises ought to be kept (and because I promised to do so). Similarly, KW would explain both Mark David Chapman's obligation not to kill John Lennon and the wrongness of his doing so - i.e., the wrongness of Lennon's murder. Why was Chapman obligated not to kill Lennon? And why was Lennon's murder wrong? Because killing is wrong.

A second thing that moral principles do is support counterfactuals, or counterfactual conditionals. ${ }^{6}$ Our next-door neighbors are away on vacation, and our neighbors across the street are feeding their cats in their absence. Given these facts, there is nothing wrong with our not feeding their cats: we have no obligation to do so. But suppose that we had promised to feed their cats in their absence. In that (counterfactual) case, we would have been obligated to feed their cats, and our not doing so would have been wrong.

POK supports this counterfactual in at least the following way: one can infer it from POK. That is, one can infer from POK that we would have been obligated to feed our neighbors' cats had we promised to do so. Moreover, POK would seem to be what makes it the case that we would have been so obligated had we so promised: we would have been obligated to feed their cats had we promised to do so because promises ought to be kept.

A third thing that moral principles do is ground moral necessities, "necessary connections" between obligating reasons - right- and wrong-making circumstances (events, states of affairs, etc.) or properties - and obligations (or rightness and wrongness tokens). If one promises to do something, it is not then a matter of chance or happenstance whether one is obligated to do it. Barring unusual circumstances (e.g., coercion), promises to $\phi$ necessitate obligations to $\phi$. Nor is it a matter of chance or happenstance that one is obligated not to kill other people. Barring unusual circumstances (e.g., selfdefense), A's being a person necessitates an obligation on $B$ 's part not to kill $A$. If I thought laws had anything to do with this, I would say that the kind of necessity involved here is nomic necessity. But since I think laws have noth-

\footnotetext{
${ }^{4}$ I borrow this phrase from Dretske $(1977,262)$. In formulating this and the next two arguments, I draw heavily on similar arguments advanced by him and by Armstrong (1983, 39$41,46-52,69-70)$ against the regularity theory of the so-called laws of nature.

5 See, e.g., Brink 1994a, 188-90, 197; Crisp 2000, 34-5; Dancy 1983, 533; Lance and Little 2008; 2007; Pietroski 1993, 499-500, 514-5; Väyrynen 2009; 2006, 716-7, 726-7. But see Jackson, Pettit, and Smith 2000, 81-4; McKeever and Ridge 2006, 6, 7-8, 12-4.

${ }^{6}$ See, e.g., Lance and Little 2007, 155-6; 2006a, 315-6, 317-8; Pietroski 1993, 492, 499-500, 514-5; Väyrynen 2009, sec. 5.
} 
ing to do with it, I will say that it is moral necessity. (In other contexts, this sort of necessity is often called "natural necessity.")

Whatever one calls it, moral necessity is neither logical nor conceptual necessity. It is necessity de re (necessity grounded in things), not necessity de dicto (necessity grounded in the meaning of words or logical form). And moral necessities are necessary connections between circumstances or properties - not logical or conceptual relations between statements, propositions, or ideas. ${ }^{7}$ My promise to remain faithful to my wife necessitates my obligation to do so. (Hence, this is singular, or token, necessitation.) Similarly, Lennon's being a person necessitated Chapman's obligation not to kill him, and my neighbors' being persons necessitates my obligation not to kill them.

These moral necessities require grounds, and they require suitably metaphysical grounds, rather than logical or conceptual ones, even if these grounds are no more than, say, social rules. Moreover, moral principles seem to be these grounds. ${ }^{8}$ For instance, POK seems to be the ground of the necessary connection between my promise to remain faithful to my wife and my obligation to do so. My promise necessitates my obligation to keep it because promises ought to be kept. And KW seems to be the ground not only of the necessary connection between Lennon's being a person and Chapman's obligation not to kill him, but also of the necessary connection between my neighbors' being persons and my obligation not to kill them. Lennon's being a person necessitated Chapman's obligation not to kill him and my neighbors' being persons necessitates my obligation not to kill them because killing is wrong.

Mere regularities can do none of these things. First, they cannot explain the phenomena falling within their scope, which are their instances. The mere fact that all $F$ s are $G$ s cannot explain the fact that a given $F$ is a $G$. For instance, suppose that all of the coins in my pocket are pennies, and name one of them Penny. The mere fact that all of the coins in my pocket are pennies cannot explain the fact that Penny is a penny. The latter fact is partly constitutive of the former fact, and hence cannot be explained by it. (Moreover, if you asked me "Why is Penny a penny?" and I answered "Because all of the coins in my pocket are pennies," you would surely think I misunderstood the question.)

Second, mere regularities cannot support counterfactuals in either of the two ways in which moral principles do. From the mere fact that all Fs are Gs, one cannot infer that this non- $G$ non- $F$ would have been a $G$ had it been an

\footnotetext{
7 One who thinks of moral principles as laws might make roughly the same point by saying that moral principles "mark the import of moral considerations...by making explicit...necessary and nontrivial connection[s]" (Lance and Little 2006b, 571) between obligating reasons and obligations.

${ }^{8}$ Might something other than moral principles (properly understood) ground moral necessities? What could do this that would not count as a moral principle (properly understood)?
} 
F. 9 For instance, from the mere fact that all of the coins in my pocket are pennies, one cannot infer that the quarter on my desk would have been a penny had it been in my pocket. And the mere fact that all $F$ s are $G$ s cannot make it the case that this non- $G$ non- $F$ would have been a $G$ had it been an $F$. For instance, the mere fact that all of the coins in my pocket are pennies cannot make it the case that the quarter on my desk would have been a penny had it been in my pocket.

Third, mere regularities cannot ground moral necessities or, more generally, necessary connections between distinct existences. Moreover, they can exist in the absence of such connections. And Humeans, who hold that the so-called laws of nature are generalizations or regularities, maintain that there are no necessary connections between distinct existences; that all relations between events, properties, etc. are purely contingent ones; and that logical and conceptual necessity are the only kinds of necessity there are.

Given that moral principles do three things that mere regularities cannot do, moral principles cannot be mere regularities. (It would, of course, suffice to show that moral principles do one thing that mere regularities cannot do.) Nor can they be generalizations describing such regularities - mere generalizations, if you will. Thus, if moral principles are generalizations at all, they must be a special class of "lawlike" generalizations. But what distinguishes "lawlike" generalizations from mere generalizations such that they can do these things? It obviously won't do to say that "lawlike" generalizations are generalizations that explain the relevant phenomena, support counterfactuals in the right ways, and ground moral necessities. What is needed is an answer to the question

What distinguishes "lawlike" generalizations from mere generalizations such that they explain the relevant phenomena, support counterfactuals in the right ways, and ground moral necessities?

And in the absence of an adequate answer to this question, we should conclude that moral principles are not moral laws.

This, then, is the main argument of the paper against the law conception of moral principles: moral principles do at least these three things that mere generalizations cannot do; hence, moral principles are not mere generalizations, and advocates of the law-conception bear the burden of explaining just what it is that distinguishes laws - "lawlike" generalizations - from mere generalizations such that they can do these things. They are not entitled to assume that such an explanation is to be had: they must provide one. And in the absence of an adequate explanation of this - in the absence of an adequate answer to our question, the question of what distinguishes laws from mere generalizations such that they can do these things - not only are we en-

9 This is not to deny that some "accidental" generalizations support counterfactuals in this first, inferential way, since not all such generalizations describe mere regularities (Armstrong 1983, 47; cf. Lange 2000, 16-7). 
titled to conclude that moral principles are not laws, we should conclude that they are not laws.

\section{The Best-Systems Theory of Moral Principles}

The law conception of moral principles mirrors - and seems modeled on - a familiar, empiricist conception of the so-called laws of nature: the regularity theory. 10 And the most prominent version of that theory is the Mill-RamseyLewis, or best-systems, theory of laws. On this view, the laws of nature are those generalizations that figure as axioms in the best deductive systems, those systems of true generalizations that strike the best balance between strength (information content) and simplicity (see, e.g., Lewis 1973, 73-5). Given that the law conception mirrors the regularity theory and that the bestsystems theory is the most prominent version thereof, we should consider whether a version of the law conception modeled on the best-systems theory could answer our question. A theory of moral principles modeled on the best-systems theory would identify moral principles with those moral generalizations that figure as axioms in the best deductive systems, those systems of true moral generalizations that strike the best balance between strength and simplicity. Call this the best-systems theory of moral principles, or BST.

Now there is nothing in BST that would explain how the axioms of the best deductive systems - which are still generalizations - could explain the relevant phenomena, support counterfactuals in the right ways, and ground moral necessities. Moreover, the best-systems theory of the laws of nature is not supposed to do analogous work. And it is open to the best-systems theorist to deny that the laws of nature explain events, support counterfactuals, or ground natural necessities - necessary connections between natural events, properties, etc. (Indeed, it is open to the best-systems theorist to deny that anything does these things.)

Now one might well think that laws of nature that did not explain events, support counterfactuals, or ground natural necessities would not be laws of nature properly so called. Hence, one might regard the regularity theory in its various incarnations as an error theory (Mumford 2004, 9). So construed, the regularity theory holds that there are no laws of nature and that the laws of science describe (certain) regularities. But this thought - the thought that such "laws" would not be laws - reflects a governing conception of the laws of nature (Beebee 2000). And it is a point of contention in the philosophy of science whether the so-called laws of nature govern events or merely describe them - whether, as Helen Beebee puts it, they "make" the facts or are "purely descriptive" of them (578).

10 According to the regularity theory, the laws of nature are generalizations or some special class thereof, such as explanatory or counterfactual-supporting generalizations. This necessarily glosses over some niceties. For instance, some versions of the regularity theory identify the laws with the relevant regularities, rather than with the propositions that describe them. 
Nor is it just Humeans who hold purely descriptive, non-governing conceptions of the laws of nature. Dispositionalists like Stephen Mumford (2004; 1998, chap. 10), Nancy Cartwright (1999; 1989), and Brian Ellis (2002; 2001) typically deny that laws govern. (Dispositionalists hold that the dispositions, or powers, of individuals explain events, support counterfactuals, and ground natural necessities.) Ellis is representative:

\footnotetext{
In my book [Ellis 2001],...I did occasionally speak of laws of nature as 'governing' various ranges of phenomena. This was loose talk, for which I apologise....

In my view, the laws of nature are...general propositions descriptive of the kinds of natural necessities that exist in [the world $]. . .[$ T $]$ hey are not items that should occur in anyone's ontology. (2006, 438, 439)
}

Moreover, the idea that the laws of nature are purely descriptive is so widespread that, as I noted above, what the term "law" generally means in the context of the literature on the laws of nature is either a "lawlike" generalization or (less often) a "nomic" regularity described by such a generalization. It does not generally mean "whatever explains events, supports counterfactuals, and grounds natural necessities." Nor does it mean "a fundamental source or basis of something," although this is one of the meanings of the word "principle" (Oxford American Dictionary).

Even though BST does not answer our question, it might be supplemented with auxiliary theories in order to do so. And it is instructive to examine both how this might be done and why this general strategy seems unlikely to vindicate the law conception of moral principles.

Recall first that moral principles such as POK support counterfactuals such as that my wife and I would have been obligated to feed our neighbors' cats had we promised to do so - in two ways. First, one can infer the relevant counterfactuals from them. Second, they (the principles) seem to be what make it the case that the relevant counterfactuals are true - my wife and I would have been obligated to feed our neighbors' cats had we promised to do so because promises ought to be kept, for example.

A proponent of BST might try to explain the ability of moral laws to support counterfactuals by appealing to David Lewis's theory of counterfactuals (cf. Beebee 2000, 576 \& n. 10). On Lewis's view, we hold the laws fixed when evaluating the truth of the relevant counterfactuals - that is, we evaluate the counterfactuals by reference to possible worlds in which the same laws obtain. And this would allow one to infer (e.g.) that my wife and I would have been obligated to feed our neighbors' cats had we promised to do so from the moral law respecting the keeping of promises (assuming one has a sufficient understanding of the content of that law), because one evaluates the former counterfactual's truth by reference to possible worlds in which we promised to feed their cats and the same moral laws obtain. 
There is also a sense in which the laws make it the case that the relevant counterfactuals are true on this view. The story goes like this: The laws are true because the occurrent facts are what they are. This is because the laws are (merely) descriptions of occurrent facts (past, present, and future). And the counterfactuals are true because the laws are what they are. This is because the possible worlds we look to in evaluating the truth of the counterfactuals are those in which the same laws obtain.

But whatever may be the case when it comes to the so-called laws of nature, when it comes to moral principles this story seems quite mistaken. According to it, the laws depend asymmetrically on the actual facts (past, present, and future), and the counterfactual facts (so to speak) depend asymmetrically on the laws. Hence, the counterfactual facts depend asymmetrically on the actual facts. Or, to put it the other way around, the actual facts determine the counterfactual facts. But while this might be the right way to think about the so-called laws of nature and their relations to actual and counterfactual facts, in the case of moral principles, both the actual facts and the counterfactual facts depend asymmetrically on the principles. Or, to put it the other way around, the principles determine both the actual facts and the counterfactual facts." This is implicit both in the idea that "morality is composed of...principles" (Hooker 2000, 2; emphasis added) and in the more controversial idea that the aim of moral theory is to identify "one first principle, or common ground of obligation" that would be "the source of obligation" (Mill 1871, chap. 1, paras. 3, 4). Moreover, it is one reason why it is so tempting to think of morality as a system of rules. For what a set of rules permits and requires in both actual and counterfactual cases depends asymmetrically on the rules that compose it: they determine what is and is not permissible within their domain of application.

It is, of course, open to a proponent of BST to come up with an alternative account of how moral laws support the relevant counterfactuals. But the principal fact remains. BST itself provides no such account: an auxiliary theory is required.

The same is true when it comes to grounding moral necessities. Here, too, an auxiliary theory is required. But what might that theory be? Lewis accounts for the connection between laws and physical necessity by defining physical necessity in terms of the laws of nature: "Physical necessity is truth at all [possible] worlds where [the] laws [of nature] hold good" $(1973,5)$. On this view, " $A$ is defined to be physically necessary if and only if it follows [logically] from the laws of nature" (Beebee 2000, 576-7). But if we do the same with moral necessity, if we define moral necessity as following (logi-

11 Cf. "What is clear is that particular moral truths are asymmetrically metaphysically dependent upon the more general moral truths stated in first principles; this is what we signal when we call them first principles" (Brink 1994a, 197); "Principles are not like theories, for theories explain what is true in particular cases without determining it, while principles determine what is true in particular cases and explain it" (Dancy 1983, 533). 
cally) from the laws of morality, we end up saying that moral necessity is necessity de dicto, when it is, in fact, necessity de re. ${ }^{12}$ Moreover, the idea that any generalization - or any regularity for that matter - could ground moral necessities seems absurd.

Finally, recall that moral principles explain the phenomena "falling within their scope," including (at least) the instances of the laws they guarantee. How might a proponent of BST explain how moral laws can explain their instances? What auxiliary theory might she appeal to?

Here Lewis is of no help, as his account of explanation is a causal account: for Lewis, to explain an event is not to subsume it under a law, but rather to give information about its causal history (1986). Nor is it any use appealing to a covering-law model of explanation, such as the DeductiveNomological (DN) model of scientific explanation favored by Carl Hempel and other logical positivists, ${ }^{13}$ for such models presuppose the explanatory power of laws. What is required is an explanation of how laws manage to have the explanatory power that mere generalizations lack - an account that would, in turn, vindicate the covering-law model. What is more, the explananda and explanantia in covering-law explanations are descriptions of events, etc. - not (e.g.) promisings and obligations; and this threatens to collapse explanatory relations between events, properties, etc. into what Hempel and the logical positivists hoped to reduce them to, vir. logical relations between descriptions (Kim 1994, 55; Cartwright 2004, 4-5). Hence, the account offered must avoid this collapse (or else explain why we should bite this bullet).

Here an advocate of BST might - following Jaegwon Kim - say that covering-law explanations succeed, when they do, by tracking (asymmetric) metaphysical dependence relations, such as causal relations and right-making relations (Kim 1994, 67-8). On this view, covering-law explanations work by depicting metaphysical dependence relations between token events, properties, etc. And these dependence relations both "ground the explanatory relation[s] between...descriptions" and "serve as the objective correlates of [covering-law] explanations" (56, 67). Hence, the statement "I promised to $\phi$ " explains the statement "I am obligated to $\phi$ " in virtue of a metaphysical obligating (or right-making) relation existing between my having promised to $\phi$ and my being obligated to $\phi$ qua circumstance tokens (or between my $\phi-$ ing's being the keeping of a promise and its rightness qua property tokens). And what moral laws do is depict the metaphysical dependence relations that exist between obligations (or rightness and wrongness tokens) and obligating reasons - e.g., between obligations to $\phi$ and promises to $\phi$.

12 We also render trivial the idea that moral laws are themselves necessary: on this view, such laws are necessary only in that they follow from themselves (cf. Lance and Little 2007, 160).

13 The DN model is now widely rejected. For a critical overview of the DN and other models of scientific explanation, see Woodward 2008. 
This is fine as far as it goes - although one might object that neither the covering-law model nor the lawlike generalizations that figure in it are doing any real work on this view. (One might also object that there is no reason to think that the generalizations that BST says are laws will, in fact, depict the relevant dependence relations.) But, in any case, it does not vindicate the law conception of moral principles. For to take this view is to take the view that the explanatory power of moral laws is derivative: it derives from the explanatory power of either the relevant dependence relations themselves or as seems more likely - the properties or relations that ground those dependence relations. In the causal case, to say that causal laws are explanatory because they depict causal relations between causes and effects is to say that their explanatory power derives either from the causal relations they depict or from the properties or relations that ground those causal relations - e.g., from causal powers or relations between universals. And, in the moral case, to say that moral laws are explanatory because they depict obligating relations right- and wrong-making relations - between obligating reasons and obligations is to say that their explanatory power derives either from the obligating relations they depict or from the properties or relations that ground those obligating relations - e.g., from obligating powers or relations between universals.

Why is this a problem for the law conception? Because whatever those explanatory properties or relations are will - at least in this respect - be better suited to be moral principles than will any generalizations that derive their explanatory power from them. In other words, the obvious thing to say here is that the real moral principles, the ones that explain the relevant phenomena, are those properties or relations - the ones from which explanatory generalizations derive their explanatory power - because they are the ones doing the real work, the explanatory heavy lifting. Moreover, this is especially true if those properties or relations are powers or relations between universals.

The same can be said mutatis mutandis about the (supposed) ability of lawlike generalizations to support counterfactuals or ground moral necessities. If lawlike generalizations do not support counterfactuals or ground moral necessities in their own right, but rather derive their ability to do so from other things, such as properties or relations, then those other things are - at least in these respects - better suited to be moral principles because they are doing the real work of supporting the counterfactuals in the right ways and grounding the moral necessities.

Here, then, is why this general strategy of supplementing BST - or, indeed, any version of the law conception - with auxiliary theories seems unlikely to vindicate the law conception of moral principles. It seems likely that any plausible account of how "lawlike" generalizations manage to explain the relevant phenomena, support counterfactuals in the right ways, and ground moral necessities will appeal to other things that do all of those same things but in their own right (e.g., powers or relations between universals) and, hence, are better suited to be moral principles than are "lawlike" generaliza- 
tions. This is a conjecture, of course - a hypothesis. But it is certainly a plausible one.

\section{McKeever and Ridge's "Action-Guiding Standards"}

In this and the following two sections, I consider whether the competing theories of moral principles recently proposed by Sean McKeever and Michael Ridge (2006), Pekka Väyrynen (2006; 2008; 2009), and Mark Lance and Margaret Little $(2008 ; 2007 ; 2006 a ; 2006 b)$ vindicate the law conception of moral principles - whether they have the resources not only to answer our question, but also to answer it in a way that vindicates the law conception of moral principles. And I will show that none of them do.

McKeever and Ridge defend "traditional moral philosophy," which they conceive as the search for "action-guiding standards" for the application of moral concepts or predicates $(2006,3,6,22-4) .{ }^{14}$ A generalization counts as a standard on their view if it

articulates true application conditions for a given moral concept by referring to those features of the world which explain why the concept applies when it does[,]...features which are of direct moral relevance - reasons for action, so-called 'defeaters' and 'enablers', and the like. (6)

It counts as a guide if it is "suitab[le] for guiding actions" - that is, if it "provide[s] useful direction to a conscientious moral agent," or leads her "to perform the right action for the right reason(s)" $(6,8)$. They focus on moral concepts and predicates, rather than moral properties or particular moral facts or truths, in order to articulate a conception of moral principles that is available to moral realists and moral anti-realists (esp. Hare) alike $(10,13)$. And they specifically deny that moral principles so understood "must themselves figure in the explanation of why a moral concept applies when it does," or of "why...particular moral truths [are] true rather than vice versa" (7). 15

Thus, their theory of moral principles does not answer our question. Nor does it purport to. One might argue that their "action-guiding standards" can explain the relevant phenomena either in virtue of depicting metaphysical dependence relations, à la Kim (see p. 9 above), or in virtue of referring to features of the world that explain why moral concepts apply when they do. But, in either case, the resulting view would amount to a conception of moral principles of just the type we found unsatisfactory in section 3: one on which moral principles are explanatory generalizations but on which their explanatory powers derive from those of other things that ex-

${ }^{14}$ Cf. Jackson, Pettit, and Smith's (2000) conception of moral principles.

15 They do acknowledge the view that moral principles explain particular moral truths. But they lay it aside, saying that the question of whether it is true is "orthogonal to th[e] question" of whether "the centuries old tradition of moral theorizing is somehow defective" (13). 
plain the very same phenomena in their own right and, hence, are - at least in this respect - better suited to be moral principles. Moreover, features of the world that do what moral principles do - explain the relevant phenomena, support counterfactuals in the right ways, and ground moral necessities in their own right - would either be or ground those features of the world that explain why moral concepts apply when they do, and to which McKeever and Ridge's action-guiding standards aim to refer.

\section{Väyrynen’s “Hedged” Generalizations}

Pekka Väyrynen proposes that moral principles are "hedged" generalizations that purport to identify moral reasons and, in particular, obligating reasons; that count as substantive moral principles because they purport to identify such reasons; and that explain why the moral reasons they purport to identify are such reasons $(2006,727-8 ; 2008$, sec. 5; 2009, secs. 4-5). The theory is complex, and Väyrynen has amended it over time; so I will confine my discussion to those details relevant to the present discussion.

Väyrynen advances the following theses about obligating and other moral reasons and their relation to moral principles:

(1) Every reason has a "normative basis," although this can be the reason itself $(2006,719,721-2)$.

(2) A reason's normative basis is "the source and explanation" of its being the kind of reason it is (719).

(3) The normative basis of a reason is not a generalization, but rather a "property, relation, or the like" (719).

(4) Moral principles are generalizations that explain why reasons are reasons by referring to their normative bases (727-8).

(5) "The normative basis of any moral reason requires the existence of a true moral principle" (728).

Notice that, on this view, the normative bases of moral reasons - the properties, relations, etc. that are the sources and explanations of their being such reasons - do the real explanatory work. Yes, on this view moral laws do explain why moral reasons are such reasons. ${ }^{16}$ But their ability to do this is evidently derivative of the fact that they refer to the normative bases of moral reasons, which bases are themselves the sources and explanations of moral reasons in the sense that a moral reason is the moral reason it is when and

16 They do this in at least the following sense: they have a role to play in enabling certain factors to constitute informative answers to "why questions." In particular, they "exhibit systematic patterns of counterfactual dependence" between the fact that there is a moral reason and those factors that could be cited to explain why there is such a reason (2009, sec. $5)$. 
because it instantiates the appropriate normative basis (Väyrynen 2009, sec. $3 ; 2008,87)$. Moreover, on this view, moral reasons require moral laws, not in the sense that moral laws are the metaphysical grounds of moral reasons, but rather in the sense that the truth of (1) guarantees that for every circumstance or property that can be a moral reason, there is a true (hedged) generalization about when and why it is such a reason that refers to its normative basis (2009, sec. 5).

But we should look a bit further into the details of the theory. Väyrynen's most recent proposal is that moral principles could be (hedged) generalizations of the following (schematic) form:

(HP) Any $x$ that is $G$ is $M$, provided that $x$ instantiates the designated normative basis of $G$ 's contribution to $M .{ }^{17}$

For example, the moral principle expressed or conveyed by "Causing pain is wrong" could be that any token act of the type causing pain is pro tanto wrong in virtue thereof provided that it (also) instantiates the normative basis for causing pain's being a (contributory) wrong-making reason - i.e., provided that it is (also) a token of that basis type $(2008,87)$. Given what a normative basis is, this implies not that causing pain is always a wrong-making reason, but rather that it is one when and because it instantiates the normative basis for being such a reason - i.e., when and because it is (also) a token of that basis type. 18

But how does this work? Suppose that "if causing pain is wrong-making, this is when and because causing pain produces something intrinsically bad" (2008, 86). In other words, suppose that tokens of the type causing pain are wrongmaking reasons when and because they are (also) tokens of the type producing something intrinsically bad. In that case, the latter factor - producing something intrinsically bad - is the source and explanation of the former factor's being a wrong-making reason when it is one: it is the normative basis for causing pain's being a wrong-making reason. And it is only when and because a token instance of causing pain instantiates this normative basis, or constitutes a case of producing something intrinsically bad, that causing pain is a wrong-making reason.

But now how does the instantiation of this normative basis $(B)$ by a token instance of causing pain $(A)$ make it wrong? How, that is, does $A$ 's instantiating $B$ make $A$ wrong? And what is the ground of the explanatory, wrongmaking relation between $A$ 's instantiating $B$ and $A$ 's being wrong?

Väyrynen's theory seems consistent with a number of different answers to these metaphysical questions. It could be that there is a rule (e.g., a divine command, a precept of reason, or a social rule) prohibiting us from produc-

17 See Väyrynen 2009, sec. 4; cf. 2008, 87; 2006, 719.

18 This requires some amendment, as Väyrynen now allows that a factor could fail to be a reason even when it instantiates the normative basis for being one (2009, sec. 3). But he has yet to say how he would amend it. 
ing things that are intrinsically bad such that $A$ is a violation of this rule in virtue of instantiating $B$. Or it could be that there is a relation of necessitation between $B$ and wrongness qua universals such that $A$ 's instantiating $B$ necessitates $A$ 's being wrong, as on Armstrong's (metaphysical) theory of laws. Or it could be that $B$-type acts - acts that produce things that are intrinsically bad - are disposed to be wrong, that $A$ is disposed to be wrong in virtue of instantiating $B$, and that $A$ 's wrongness is the manifestation of this disposition or the outcome thereof (cf. Robinson 2006, 352-3; Ross 1930, 19-20, 28-9; 1939, 86).19 (Indeed, Väyrynen's claim that every moral reason has a normative basis, although this can be the reason itself, is reminiscent of the claim that every causal disposition has a causal basis, although this can be the disposition itself.20) And however we fill in the details of how $A$ 's instantiating $B$ makes $A$ wrong, the explanatory power of the relevant "hedged" generalization will derive from something else that grounds the explanatory, wrong-making relation between $A$ 's instantiating $B$ and $A$ 's being wrong - be it a rule, a relation between universals, a disposition, or what have you.

What we have here, then, is a conception of moral principles on which moral principles are explanatory generalizations that derive their explanatory powers from those of other things that explain the very same phenomena in their own right and, hence, are - at least in this respect - better suited to be moral principles. Moreover, whatever story we tell about what it is that grounds the explanatory relations between obligating reasons qua instances of their normative bases and the moral facts they explain (whether we say those grounds are rules, relations between universals, dispositions, or what have you), it seems likely that whatever those grounds are will be better suited to be moral principles than will Väyrynen's "hedged" generalizations. For not only will they explain the relevant phenomena in their own right; they will most likely also support counterfactuals in the right ways and ground moral necessities.

\section{Lance and Little's "Defeasible" Generalizations}

We turn now from three avowed "generalists" to two erstwhile "particularists."21 Mark Lance and Margaret Little propose a "pragmatist" (2007, 155)

\footnotetext{
19 Or it could be that wrongness consists in producing something intrinsically bad such that $A$ is wrong simply in virtue of instantiating $B$ (cf. Väyrynen 2006, 721). This list of possibilities is not meant to be exhaustive.

20 Moreover, Väyrynen now allows that a factor could fail to be a reason even when it instantiates the normative basis for being one (2009, sec. 3$)$. And this is easily accommodated on a dispositional account of the metaphysics of moral principles and right-making reasons, since dispositions can be prevented from manifesting by other factors (see Robinson MS; 2006, 344).

${ }^{21}$ Lance and Little no longer regard themselves as "particularists," but rather as "deep contextualists" who are not "anti-generalist," but rather "anti-principlist" in that they reject the idea that moral principles must be "exceptionless covering law $[\mathrm{s}]$ " in order to be covering
} 
theory of moral principles according to which moral principles are "defeasible" generalizations or laws, "lawlike" generalizations that hold true in cases that we privilege "in one way or another" $(2008,62$; 2006a, 311), or rather in cases that we qua moral theorists privilege in one way or another because doing so serves our pragmatic purposes. They present this as an account of the semantics of moral principles, an account of what such principles say (2008, $54 ; 2007,150 ; 2006 a, 311 ; 2006 b, 589)$. And what moral principles say on this account is (roughly) that in privileged conditions, all Fs are $G$ (2006b, 589; cf. $2007,152)$ - that, for example, the principle that lying is wrong says

that, in privileged conditions, lying is at least wrong-making: that is, in privileged conditions, the fact that something counts as a lie counts against doing it, even if that count is ultimately outweighed by other exigencies. $(2007,153)$

However, they also offer a "pragmatist" account of "lawlikeness," one that is intended to be an alternative to "metaphysical" accounts of laws, including the view that laws are grounded in relations between universals, 22 and also to something very much like BST $(2007,155 ; 2006 b, 571)$.

Following Marc Lange (2000), Lance and Little claim that what distinguishes laws from other "explanatory or theoretical generalizations" is their "counterfactual robustness," or "necessity," and their "particularly forceful kind of inductive confirmability" (2007, 155-6; cf. 2006a, 316, 317-8). On this view, laws are a "special kind" of explanatory or theoretical generalization distinguished from other such generalizations by two things:

(1) their counterfactual implications and, in particular, their ability to support inferences about "a particularly broad range of counterfactuals" (2007, 156; 2006a, 316);

(2) the fact that "each [of their] instance[s]... receives some degree of inductive confirmation from any [of their] confirming instance[s]" (2007, 156; cf. 2006a, 316, 318).

Moreover, these are not just marks of lawlikeness: on this view, "what it is for a given generalization to be a law just is for it to be a true generalization capable of serving the specialized inferential functions thus demarcated" (2007, 156).

laws at all (2008, 54 \& n. 5, 73). However, their views about moral principles have not changed significantly from when they billed themselves as "particularists."

${ }^{22}$ Lance and Little read Armstrong as holding that "laws are grounded in identities between universals" (2007, 155). But unless Armstrong has recently changed his views quite radically, this is a misreading. The view for which he is famous is that laws are contingent relations of necessitation between distinct universals, and he explicitly denies that property identities are laws (see Armstrong 1983, 138; 2005, 315-6). However, he has claimed that dispositions are contingently identical to their bases $(1996,39)$ and that dispositions are nothing more than the relations between universals he takes laws to be $(2005,315)$. 
Not surprisingly, given its pragmatistic nature, this account of lawlikeness does not answer our question: what distinguishes "lawlike" generalizations from mere generalizations such that they explain the relevant phenomena, support counterfactuals in the right ways, and ground moral necessities? It is obviously no answer to this question to say that laws are distinguished from mere generalizations not only by their explanatory power, but also by the particularly broad range of counterfactuals for which they provide inferential support and by their particularly forceful kind of inductive confirmability. Nor do Lance and Little pretend otherwise.

Indeed, it seems that, in keeping with pragmatism, Lance and Little intend for their account of lawlikeness to be neutral on the further question of why laws have the traits they regard as constitutive of lawlikeness, and even on whether there is a non-trivial answer to this question:

On the pragmatist approach [to thinking about laws],... one begins with what special epistemic function lawlike generalizations serve. While one can go on to ask of such generalizations what aspects of reality they capture (a question to which there may or may not be a non-trivial answer), the central issue that demarcates something as a law instead of some other sort of theoretical generalization is given in terms of the role the claim plays in the functional structure of epistemology. $(2007,155)$

Nevertheless, we should consider whether they have any further resources with which to answer our question. For Lance and Little are the principal defenders of the view that explanatory generalizations are essential to moral theory and moral epistemology.

We might start with their view about the semantics of moral principles. Do Lance and Little's defeasible laws do some or all of the things that moral principles do given that what some of them say is that certain features are obligating reasons in privileged conditions?

They might do some of them if Lance and Little had either a suitable (non-pragmatistic) account of what it is to be an obligating reason or an account of what it is that grounds the obligating relations between obligating reasons and obligations. But even so, to say that defeasible laws do some or all of the things that moral principles do given what they say is to pass the explanatory, counterfactual-supporting, and/or necessity-grounding buck on to whatever "aspects of reality" do those same things but in their own right. Hence, on this interpretation, Lance and Little's view would be yet another on which moral laws derive whatever ability they have to do what moral principles do from other things that are - at least in those respects - better suited than they are to be moral principles.

What about Lance and Little's argument for the claim that defeasible laws "can function as genuine explanatory laws" (2006a, 316)? The problem here is the way in which they argue for this claim. They argue for it by arguing that the defeasible character of defeasible laws does not prevent them from satisfying their account of lawlikeness (2006a, 316, 317-8; cf. 2007, 156, 
158). Hence, the argument takes both their account of lawlikeness and the explanatory power of laws as given.

What about the following argument for the claim that "reasons and explanation...have something to do with generalization, even if the connection is not a deductive one"?

\begin{abstract}
Whatever the details, something counts as explanatory when it serves a particular epistemic function, namely, when it can serve in particularly robust ways (with 'robust' interpreted differently by different theorists) as the basis of an inference to the conclusion. This is what ties the idea of something being a reason to something that can serve in reasoning. But to play this role requires hooking in to generalization. To be committed to the propriety of any inference (whether explanatory or not) is to be committed to its propriety in some set of other contexts. (2008, 59; cf. 2006b, $587 ; 2006 a, 309)^{23}$
\end{abstract}

For our purposes, the relevant claim here is that in order for something to be explanatory in one context, it must also be explanatory in other contexts. Is this true? And would it follow either that moral laws are explanatory or that moral principles are moral laws?

Presumably, the claim here is not that there cannot be unique explanations of unique explananda, but rather that $x$ cannot be explanatory of $y$ in one context unless $x$-type properties (or what have you) would also be explanatory of $y$-type properties in other, relevantly similar contexts. Fair enough: explanations are universalizable (Sidgwick 1907, 208-9, 379-80; cf. Hare 1981, 7-8, 10, 21) - although we do need to allow for probabilistic explanations in some domains, as well as for brute, inexplicable facts. But what follows? It might follow that moral principles properly understood explain whatever particular moral facts there are (cf. Robinson 2006, 351-2). Beyond that, it follows that if $x$ explains $y$, then there is a true generalization, $G$, quantifying over $x$-type properties, $y$-type properties, and relevantly similar contexts. But it does not follow that $G$ explains $y$. Nor does it follow that $G$ or any other generalization is a moral principle. For it is consistent with the foregoing that moral principles properly understood are (e.g.) rules, relations between universals, or dispositions, rather than laws.

What about the following suggestion?

The point of [explanatory] generalizations seems to involve isolating a connection that is, for one reason or another, particularly telling of something's nature. (2006b, 569-70; see also 2008, 62; 2006a, 310-1)

23 They do not mean to say that the ability to serve as the basis of an inference that something is the case is sufficient for being explanatory of why it is the case $(2008,60)$. Rather, their view is that the criteria for whether something counts as explanatory are epistemic, not metaphysical (2008, 61; 2006b, 587; 2006a, 309). 
Borrowing one of Lance and Little's own examples, we might take the point of the defeasible law "Fish eggs develop into fish" to be isolating something about a connection between fish eggs and fish that is particularly telling of the formers' natures (2006a, 317) - namely, that fish eggs are disposed by their intrinsic natures to develop into fish. And, given that natures are explanatory, certain defeasible laws might be held to be explanatory in virtue of their providing relevant information about natures, such as that fish eggs are disposed by their intrinsic natures to develop into fish (cf. Ellis 2001, 167-70; 2002, 154-7), or that promise-keepings are disposed by their intrinsic natures to be obligatory (cf. Robinson 2006, 352-3; Ross 1930, 19-20, 28-9; 1939, 86). Indeed, this is very close not only to Ellis's view that the fundamental laws of nature (so-called) describe "the ways in which things belonging to natural kinds must be disposed to act or interact, given their essential properties" $(2001,106)$, but also to Cartwright's view that the laws of physics (socalled) describe the natural capacities or powers of physical systems - i.e., the ones they have in virtue of their natures (1999, chap. 4).24

But notice that on this view the explanatory power of laws derives from other things that explain the very same phenomena in their own right and, hence, are better suited to be moral principles - namely, natures and the dispositions things have in virtue of their natures. Moreover, this is not Lance and Little's view, and they dismiss without argument an Aristotelian metaphysics of "reified potential[s] by reference to which other things count as interfering factors" $(2006 a, 310)$. They evidently also reject the idea of real natures or essences, for their "pragmatist approach to kind concepts" is coordinate with, and no less pragmatistic than, their "pragmatist approach to laws" $(2007,155,165)$. On this view, we determine the "natures" of things, or at least their kind essences. Whether it is (e.g.) in the "nature" of fish eggs to develop into fish or whether "it is of the essence of lying that it is defeasibly wrong-making," or whether "the Good is, necessarily, defeasibly such as to be pursued" (2006a, 317) does not depend on facts about fish eggs or lying or the Good. Rather, it depends on facts about our pragmatic purposes and about what serves those purposes. Moreover, on this view, things count as expressions of an individual's "nature" only because it serves our pragmatic purposes to privilege them as not calling for explanations, at least not at the present level of theory (2008, 67; 2007, sec. 5; 2006a, 317). Hence, on this view, natures are not explanatory.

To conclude, Lance and Little's consistently pragmatistic view lacks the resources to answer our question - to explain what distinguishes "lawlike" generalizations from mere generalizations such that they explain the relevant phenomena, support counterfactuals in the right ways, and ground moral necessities. Moreover, even if we were to grant that their defeasible laws both explain the relevant phenomena in the purely epistemic way they intend and

${ }^{24}$ On this view, Newton's law of gravity $\left(F=G m_{1} m_{2} / r^{2}\right)$, for example, describes the powers or capacities of massive bodies qua massive, rather than any regularity (Cartwright 1999, 65, 82). 
support counterfactuals in the first, inferential way that moral principles do, their defeasible laws would still fail to support counterfactuals in the second way in which moral principles do: they would not make it the case that those counterfactuals are true. And they would still fail to ground moral necessities. Hence, they would still fail to do some things that moral principles do.

\section{Conclusion}

Moral principles are not moral laws. But what are they? Reflection on what moral principles do and on the accounts of moral principles surveyed above all point to the need, not just for things that explain the relevant phenomena, support counterfactuals in the right ways, and ground moral necessities, but also for things that do all of these things in their own right. (Or, at the very least, such reflection points to the need for moral realists to posit things that do all of these things in their own right.)

I have already mentioned three readily available alternative conceptions of what moral principles are:

(1) they are rules properly so called - e.g., divine commands, precepts of reason, or social rules;

(2) they are relations between universals (cf. Armstrong 1983; Dretske 1977);

(3) they are dispositions, or powers (Robinson 2006, sec. 6; cf. Cartwright 1999; 1989; Ellis 2002; 2001; Mumford 2004; 1998, chap. $10)$.

On any of these three alternative conceptions of moral principles they arguably do what moral principles are supposed to do.

There is some question about whether, and if so how, relations between universals might ground necessary connections between particulars. But the advocates of this view of the laws of nature argue that they can and do. Rules, on the other hand, clearly do this. They also clearly explain the phenomena "falling within their scope" and support counterfactuals in the right ways. Take the following rule of baseball, for example.

\section{(TS) Three strikes and you're out.}

Why is the batter out? Because the rule is three strikes and you're out. Would the runner on first base have been out had she gotten a third strike before getting a base hit? Yes, and one can infer this from TS. Why would the runner have been out in that (counterfactual) case? What makes it the case that she would have been out? TS makes it the case. The runner would have been out because the rule is three strikes and you're out. Why does a batter's getting three strikes necessitate her being out? What grounds this necessary connection between getting three strikes and being out? TS grounds this necessary con- 
nection. A batter's getting three strikes necessitates her being out because the rule is three strikes and you're out.

My own view, however, is that both of these conceptions of moral principles are objectionable on other grounds, and that moral principles are best conceived as moral dispositions - real, dispositional properties of individuals, such as the power of agents to obligate themselves by promising and the power of persons to obligate agents not to kill them, that are responsible for and thereby explain the moral properties of (e.g.) agents and actions, such as my obligation to remain faithful to my wife and the wrongness of Lennon's murder (see Robinson MS). But establishing these further points requires a further set of arguments. All that I have argued here is that moral principles are not moral laws - at least not so long as what we mean by a law is a generalization or regularity of some sort, rather than, say, a rule, a relation between universals, or a disposition.

Luke Robinson

Southern Methodist University

Department of Philosophy

lrobinson@smu.edu 


\section{References}

Aristotle. 1999. Nicomachean Ethics. 2nd ed. Trans. Terrence Irwin. Indianapolis: Hackett. Armstrong, David M. 1983. What Is a Law of Nature? Cambridge: Cambridge Univ. Press. . 2005. Four Disputes About Properties. Synthese 144:309-20.

Armstrong, David M., C.B. Martin, and U.T. Place. 1996. Dispositions: A Debate. Ed. Tim Crane. London: Routledge.

Beebee, Helen. 2000. The Non-Governing Conception of Laws of Nature. Philosophy and Phenomenological Research 61:571-94.

Brink, David O. 1994a. Common Sense and First Principles in Sidgwick's Methods. Social Philosophy and Policy 11:179-01. . 1994b. Moral Conflict and Its Structure. Philosophical Review 103:215-47.

Cartwright, Nancy. 1989. Nature's Capacities and Their Measurement. Oxford: Oxford Univ. Press.

1999. The Dappled World: A Study in the Boundaries of Science. Cambridge: Cambridge Univ. Press.

2004. From Causation to Explanation and Back. In The Future of Philosophy, 230-45. Ed. Brian Leiter. Oxford: Oxford Univ. Press.

Crisp, Roger. 2000. Particularizing Particularism. In Hooker and Little 2000, 23-47.

Dancy, Jonathan. 1983. Ethical Particularism and Morally Relevant Properties. Mind 92:530_ 47.

Dretske, Fred I. 1977. Laws of Nature. Philosophy of Science 44:248-68.

Ellis, Brian. 2001. Scientific Essentialism. Cambridge: Cambridge Univ. Press. 2002. The Philosophy of Nature: A Guide to the New Essentialism. Montreal \& Kingston: McGill-Queen's Univ. Press. 2006. Looking for Laws. Metascience 15:437-41.

Hare, R.M. 1981. Moral Thinking: Its Levels, Method, and Point. Oxford: Oxford Univ. Press.

Hooker, Brad. 2000. Moral Particularism: Wrong and Bad. In Hooker and Little 2000, 1-22.

Hooker, Brad, and Margaret Little, eds. 2000. Moral Particularism. Oxford: Oxford Univ. Press.

Jackson, Frank, Philip Pettit, and Michael Smith. 2000. Ethical Particularism and Patterns. In Hooker and Little 2000, 79-99.

Kim, Jaegwon. 1994. Explanatory Knowledge and Metaphysical Dependence. Philosophical Issues 5:51-69.

Lance, Mark, and Margaret Little. 2006a. Defending Moral Particularism. In Contemporary Debates in Moral Theory, 304-21. Ed. James Dreier. Malden, Mass.: Blackwell.

- 2006b. Particularism and Antitheory. In The Oxford Handbook of Ethical Theory, 56793. Ed. David Copp. New York: Oxford Univ. Press. 2007. Where the Laws Are. In Oxford Studies in Metaethics, vol. 2, chap. 7. Ed. Russ Shafer-Landau. Oxford: Oxford Univ. Press.

- 2008. From Particularism to Defeasibility in Ethics. In Lance, Potrč, and Strahovnik, 53-75.

Lance, Mark, Matjaž Potrč, and Vojko Strahovnik, eds. 2008. Challenging Moral Particularism. New York: Routledge.

Lange, Marc. 2000. Natural Laws in Scientific Practice. Oxford: Oxford Univ. Press.

Lewis, David. 1973. Counterfactuals. Cambridge: Harvard Univ. Press.

1986. Causal Explanation. In Philosophical Papers, vol. 2, chap. 22. New York: Oxford Univ. Press.

McKeever, Sean, and Michael Ridge. 2006. Principled Ethics: Generalism as a Regulative Ideal. Oxford: Oxford Univ. Press.

McNaughton, David, and Piers Rawling. 2000. Unprincipled Ethics. In Hooker and Little 2000, 256-75. 
Mill, John Stuart. 1871. Utilitarianism. 4th ed. Ed. Roger Crisp. Oxford: Oxford Univ. Press, 1998.

Molnar, George. 2003. Powers: A Study in Metaphysics. Oxford: Oxford Univ. Press.

Mumford, Stephen. 1998. Dispositions. Oxford: Oxford Univ. Press. . 2004. Laws in Nature. London: Routledge.

Pietroski, Paul M. 1993. Prima Facie Obligations, Ceteris Paribus Laws in Moral Theory. Ethics 103:489-515.

Robinson, Luke. 2006. Moral Holism, Moral Generalism, and Moral Dispositionalism. Mind 115:331-60.

. MS. Moral Principles as Moral Dispositions. Southern Methodist University.

Ross, W.D. 1930. The Right and the Good. Ed. Philip Stratton-Lake. Oxford: Oxford Univ. Press, 2002.

. 1939. Foundations of Ethics. Oxford: Oxford Univ. Press.

Shafer-Landau, Russ. 1997. Moral Rules. Ethics 107:584-611.

. 2003. Moral Realism: A Defence. Oxford: Oxford Univ. Press.

Sidgwick, Henry. 1907. The Methods of Ethics. 7th ed. London: Macmillan.

Väyrynen, Pekka. 2006. Moral Generalism: Enjoy in Moderation. Ethics 116:707-41. . 2008. Usable Moral Principles. In Lance, Potrč, and Strahovnik, 75-106. 2009. A Theory of Hedged Moral Principles. In Oxford Studies in Metaethics, vol. 4. Ed. Russ Shafer-Landau. Oxford: Oxford Univ. Press.

Woodward, James. 2008. Scientific Explanation. In Stanford Encyclopedia of Philosophy, fall 2008 ed. Ed. Edward N. Zalta.

http://plato.stanford.edu/archives/fall2008/entries/scientific-explanation/. 